\title{
Liposomal Bupivacaine
}

National Cancer Institute

\section{Source}

National Cancer Institute. Liposomal Bupivacaine. NCI Thesaurus. Code C125652.

A liposome-encapsulated formulation of bupivacaine, which is an amide-type, long-acting local anesthetic. Upon administration, bupivacaine reversibly binds to specific sodium ion channels in the neuronal membrane, resulting in both a decrease in the voltagedependent membrane permeability to sodium ions and membrane stabilization. This leads to inhibition of both depolarization and nerve impulse conduction, and a reversible loss of sensation. Compared to bupivacaine alone, liposomal delivery increases the duration of local anesthetic action and delays the peak plasma concentration of bupivacaine due to its slow release from the liposome. 